\title{
EXPERIENCES OF NURSES DIAGNOSED WITH COVID-19
}

\author{
Ruveyde $\mathrm{AYDIN}^{1}$ and ENES BULUT ${ }^{2}$ \\ ${ }^{1}$ Karadeniz Technical University \\ ${ }^{2}$ Artvin Coruh Universitesi
}

February 19, 2021

\begin{abstract}
Aim: This study aimed to explore the experiences of nurses who were diagnosed with coronavirus-19 and received treatment from their perspective. Background: Coronavirus-19 has caused many people to become sick and die. Nurses who struggle with coronavirus-19 in the forefront have been physically and psychologically influenced by the pandemic, and many nurses were diagnosed with coronavirus-19 and even died. Methods: A descriptive qualitative approach was used. The study was conducted with 18 nurses diagnosed with coronavirus-19, and the data were collected using a semi-structured individual interview form. The data were analysed with the thematic analysis technique using Meleis et al.'s mid-range theory on experiencing transitions. COREQ Checklist was followed as EQUATOR Checklist. Results: Nurses' experiences when diagnosed with coronavirus-19 have been examined under 6 main themes as emotions experienced when finding out to be coronavirus-19 positive, the emotions during the quarantine process, posttraumatic growth, methods of coping with coronavirus-19, nursing care after coronavirus-19 treatment, and metaphors about coronavirus-19. Conclusion: The study revealed that nurses diagnosed with coronavirus-19 experienced fear, loneliness, frustration, depressed mood, exclusion, and fear of death. Besides, after coronavirus-19 treatment, they experience posttraumatic growth such as spiritual change, changes in the relationship with others, changes in priorities, and appreciation of the meaning of life. They cope with adverse situations caused by coronavirus-19 by getting social support, positive thinking, paying attention to nutrition, and engaging in domestic activities. Besides, they perform their nursing care after coronavirus-19 with more empathy and emphasizing the psychological aspect of care. Relevance to clinical practice Being diagnosed with coronavirus-19 has caused the nurses to be negatively affected psychologically (fear, depression, loneliness, etc.). It is recommended to provide professional psychological counselling services to nurses during the pandemic and maintain these services $24 / 7$.
\end{abstract}

\section{EXPERIENCES OF NURSES DIAGNOSED WITH COVID-19}

\section{ABSTRACT}

Aim: This study aimed to explore the experiences of nurses who were diagnosed with coronavirus-19 and received treatment from their perspective.

Background: Coronavirus-19 has caused many people to become sick and die. Nurses who struggle with coronavirus-19 in the forefront have been physically and psychologically influenced by the pandemic, and many nurses were diagnosed with coronavirus-19 and even died.

Methods: A descriptive qualitative approach was used. The study was conducted with 18 nurses diagnosed with coronavirus-19, and the data were collected using a semi-structured individual interview form. The data were analysed with the thematic analysis technique using Meleis et al.'s mid-range theory on experiencing transitions. COREQ Checklist was followed as EQUATOR Checklist.

Results: Nurses' experiences when diagnosed with coronavirus-19 have been examined under 6 main themes as emotions experienced when finding out to be coronavirus-19 positive, the emotions during the quarantine 
process, posttraumatic growth, methods of coping with coronavirus-19, nursing care after coronavirus-19 treatment, and metaphors about coronavirus-19.

Conclusion: The study revealed that nurses diagnosed with coronavirus-19 experienced fear, loneliness, frustration, depressed mood, exclusion, and fear of death. Besides, after coronavirus-19 treatment, they experience posttraumatic growth such as spiritual change, changes in the relationship with others, changes in priorities, and appreciation of the meaning of life. They cope with adverse situations caused by coronavirus19 by getting social support, positive thinking, paying attention to nutrition, and engaging in domestic activities. Besides, they perform their nursing care after coronavirus-19 with more empathy and emphasizing the psychological aspect of care.

\section{Relevance to clinical practice}

Being diagnosed with coronavirus-19 has caused the nurses to be negatively affected psychologically (fear, depression, loneliness, etc.). It is recommended to provide professional psychological counselling services to nurses during the pandemic and maintain these services $24 / 7$.

Keywords: Coronavirus-19, pandemic, nurse, coronavirus-19 diagnosis, nursing care

\section{INTRODUCTION}

The new coronavirus disease (COVID-19), which first broke out in Wuhan, China, in December 2019, soon spread throughout the world (Gashi, 2020; Zhang et al., 2020). The World Health Organization reports that more than 70 million people became sick, and 1.6 million patients died due to COVID-19 worldwide by December 2020 (WHO, 2020). Since the first confirmed case on 11 March 2020 in Turkey, 1,898,447 people have got sick, and 16881 people died (T. R. Ministry of Health, 2020).

The Turkish government has quickly set out regulations in the health care system with the outbreak felt in Turkey. With these regulations, many clinics started to serve as COVID-19 clinics, and nurses from various specialties and clinics were assigned in these clinics (Çelik et al., 2020). Nurses' leave plans have been postponed preventing labour shortages (Sun et al., 2020). Because of their frequent contact with patients, nurses carry a high risk of getting and transmitting the virus. Therefore, especially in the early days of the pandemic, nurses were accommodated in institutions such as hotels, guesthouses, dormitories, etc. (Zhang et al., 2020).

With the regulations put into force both to prevent the loss of the nursing workforce and to ensure social isolation, Turkey has taken important steps to prevent the spread of COVID-19 (Karasu \& Çopur, 2020). However, these regulations exposed nurses to undesirable situations. Working long hours with patients with different prognostic characteristics in unfamiliar units and not being able to use their leave rights caused the nurses to have anxiety and burnout syndrome (Karasu \& Çopur 2020). Nurses experienced psychological problems such as depression and restlessness due to their stay in places away from their families and friends without doing any social activities, especially in the initial period of the pandemic (Zhang et al., 2020). Nurses are also seen as a group to be avoided due to their potential for virus transmission in the society, and they were excluded, which has been effective in aggravating negative psychological symptoms in nurses (Karasu \& Çopur 2020).

Nurses play significant roles in the front lines in controlling the pandemic and providing patient care. Being in close contact with patients diagnosed with COVID-19 causes nurses to feel the fear of becoming infected and infecting their relatives. Indeed, many nurses have been diagnosed with COVID-19 and infected their families (Çelik et al., 2020; Schwartz et al., 2020). In addition to having to cope with the physical and psychological symptoms caused by the disease, nurses diagnosed with COVID-19 had to return to work soon before they could fully regain their health due to the need for a nursing workforce. This situation can negatively affect both the quality of life of nurses and the quality of care given to patients. Considering this information, this study was conducted to determine the experiences of nurses diagnosed with COVID-19.

\section{BACKGROUND}


The most significant concept of Meleis' Transition Theory is the type and property of transition (Meleis et al., 2000). The transition type in this study is health-illness and single transition (Figure 1). Transition is the process of moving from one stable state to another. However, this process takes place by being influenced by various facilitating and inhibiting factors (personnel, community, society) (Meleis, 2010). In this study, while the facilitating factors were identified as hoping, being a nurse, and social support, inhibiting factors were found as loneliness, frustration, fear of death, the severity of symptoms, exclusion, death news on social media, being a nurse, having a child, and the fear of infecting the family. The success of a transition is determined by a person's involvement, which is affected by personal factors, including meaning, awareness, engagement, and preparation and knowledge (Meleis et al., 2000). Meaning "refers to the subjective appraisal of an anticipated event and the evaluation of its effect on one's life" (Schumacher \& Meleis, 1994). Awareness "is related to perception, knowledge and, and recognition of a transition experience" (Meleis et al., 2000). Engagement shows "the individual's participation in the transition process. If the individual is aware of his/her situation, $\mathrm{s} /$ he takes responsibility". Change and difference "indicate that it is essential to define the meaning and effects of the change and difference that the transition brings to make sense of the transition process" (Schumacher \& Meleis, 1994). Preparation and knowledge are about "what to expect during a transition and what strategies may be helpful" (Schumacher \& Meleis, 1994). Besides, a successful transition is characterized by process and outcome indicators. Process indicators are characterized by a sense of attachment, interaction, selfconfidence, and developing coping methods (Meleis, 2010). Nurses in this study reported that they better understood the value of life after the diagnosis of COVID-19, became more attached to life, and coped with adverse situations caused by the disease by thinking positively and engaging in domestic activities. Outcome indicators are mastery and fluid integrative identities. Mastery is the blending and application of the things that people have learned or realized their importance when they move to a new state. In this study, nurses understood the importance of empathy and psychological care during COVID-19 treatment and the quarantine process and then reflected these experiences to nursing care. Fluid integrative identities are recognizing, regaining, or experiencing a change in one's identity (Meleis et al., 2000; Meleis, 2010). In this study, nurses stated that they experienced posttraumatic growth, experienced changes in their relationships with others and priorities in life, started to give more importance to spiritual and religious issues and understood the value of life (Figure 1).

"Figure 1 here"

\section{METHOD}

\subsection{Study design}

A descriptive qualitative research design was used in this study. A descriptive qualitative study aims to determine the factors associated with a certain phenomenon, how these factors affect it how the participants are affected by this phenomenon (Silverman, 2005).

\subsection{Participant and setting}

The research population comprised COVID-19 positive nurses working in pandemic hospitals in Turkey. The sample of the study included those who were diagnosed and treated for COVID-19, experienced moderate or severe symptoms of COVID-19, and volunteered to participate in the study (Table 1).

\section{"Table 1 here"}

The snowball technique, one of the purposeful sampling methods in qualitative research, was utilized in the study. The snowball technique is a sampling method in which people with similar experiences are selected according to the general criteria set by the researcher, and these selected individuals are requested to nominate a friend who complies with the research criteria and volunteers to participate in the study (Ghaljaie et al., 2017). In qualitative research, the sample size is determined according to the saturation point. It means that the saturation point is reached when the information obtained during the interview starts to repeat or when no new information is revealed (Morse, 2015). In this study, data saturation was achieved with 18 nurses.

\subsection{Data collection}


The data were collected between December 2020 and January 2021. A "Descriptive Information Form" and a "Semi-Structured Interview Form" were used to collect data. The descriptive information form consists of six questions investigating sociodemographic characteristics such as age, educational status, marital status, etc. The semi-structured interview form, including seven questions, and used in in-depth individual interviews, was prepared based on the main concepts of Meleis' Transition Theory (Meleis, 2010) (Table 2).

In-depth individual interviews were conducted over the phone due to the COVID-19 pandemic. Prior to the interview, the participants were called and informed about the purpose of the study, that the interview would be conducted over the phone and that the audio recording would be made, and interviews were made with those who volunteered to participate in the study at the appropriate day and time. After the descriptive information form was applied, all participants were asked the opening question "How did you feel when you learned that you were COVID-19 positive?" to start the interview. Sub-questions were also used to allow the participants to explain their experiences in detail and to encourage them. The duration of the meeting varied between 30-50 minutes, depending on the participant.

\section{"Table 2 here"}

\subsection{Data Analysis}

The analysis of qualitative data was made based on Braun and Clarke's (2014) thematic analysis approach consisting of six steps. The first step is to read the data multiple times so that the researchers become familiar with the data and identify remarkable statements about the participants' experiences. In the second step, all the common expressions are put together to generate the initial codes, list them, and organize the data into meaningful groups. Thirdly, certain themes are created to put together similar initial codes. In the fourth step, the created themes are revised and improved. The fifth step is to define themes and sub-themes and explain which aspect of the data is effective in determining themes. In the last step, the analyses are reported. The appropriateness of the themes emerging as a result of the analysis is checked by two external experts.

\subsection{Rigour}

In this study, Lincoln and Guba's Evaluative Criteria were used to check for accuracy and reliability of data, including credibility, dependability or trust, conformability, and transferability. (1) For credibility, the interviews were continuously carried out actively, and sufficient time was allocated to the interviews. (2) For dependability, opinions of experts in the relevant field were consulted during the preparation of the semistructured interview form and the analysis of the data. (3) For conformability, two experts were consulted about the appropriateness of main themes and subthemes. (4) For transferability, the purposeful sampling method was utilized to collect data from a suitable and large sample, and maximum diversity was taken into account. Researchers' assumptions were not included in the data collection and analysis process as much as possible (Creswell, 2013).

\subsection{Ethical Considerations}

Approval was granted by the Turkish Ministry of Health COVID-19 Research Assessment Commission (Confirmation code: 12-11T13-59-28) and Institutional Review Board. Before the interview, they were informed about the purpose of the study, that the data would be collected by phone and the interview would be recorded, that they could withdraw the interview any time they wanted, and their verbal consent was obtained. These verbal consents are available in the audio recordings. COREQ Checklist was followed as EQUATOR Checklist.

\section{RESULTS}

Experiences of nurses when they were diagnosed with COVID-19 were examined under six main themes; emotions experienced when they learned that they were COVID-19 positive, the emotions during the quarantine process, posttraumatic growth, meaning of life, coping methods with COVID-19, nursing care after being positive for COVID-19 and metaphors of COVID-19. 


\section{"Table 3 here"}

\subsection{Main Theme 1. Emotions when diagnosed with positive COVID-19}

The emotions of nurses when they found out that they were COVID-19 positive were examined under two sub-themes as fear-sadness and anger.

\subsubsection{Subtheme 1.1. Fear and sadness}

Most nurses $(\mathrm{n}=16)$ stated that they experienced fear and sadness when they learned that they were COVID19 positive, and as they are healthcare professionals, they are aware of the potential of the disease course getting worse suddenly, intensive care treatment process, or the possibility of infecting the family and the other people.

"I visited my mother at the weekend... what if I had infected my neighbour and them... I was very scared, very sad... The COVID patient is not like a normal intensive care patient. The person I talked to one day could be intubated the next day and could be dead the other day..." (N14)

"You have fears. Because while the course of the disease is good, it can suddenly get worse ... I wonder if the disease progresses. Will it go deep into my lungs? If I can't breathe at all, will a tracheostomy be opened? ... You always think about them, and you are afraid if it happens to me..." (N10).

One of the nurses who infected her family with the virus expressed her sadness as follows;

"I was very sorry. I live with my family, I cried a lot, wondering if I had infected them, and I had infected my father. That's why I was so sorry..." (N5)

\subsubsection{Subtheme 1.2. Anger}

Some of the nurses $(n=2)$ stated that when they first learned that they were COVID-positive, they experienced anger due to the delay in testing and the possibility of getting sick and infecting the others as follows;

"I felt great anger... I had severe muscle pain, I couldn't stand... They didn't collect a sample because I had no fever. I worked with that pain for a few days. Finally, I went to a private hospital, and I was positive. I looked after my patients for a few days. Therefore, I felt great anger ..." (N1)

"I had symptoms for a few days, but I couldn't get tested as I had no fever. Then I got a fever. The moment I found out, I got very angry because they hadn't tested earlier. Because in those days I had dinner with my colleagues and looked after my patients..." (N3)

\subsection{Main Theme 2. Emotions during the quarantine}

The experiences of nurses during the quarantine process were experienced under five sub-themes: loneliness, frustration, depressed mood, fear of exclusion, and fear of death.

\subsubsection{Subtheme 2.1. Loneliness}

Some of the nurses $(\mathrm{n}=6)$ expressed that they felt loneliness during the quarantine as follows;

"Loneliness is the primary emotion you feel. You can touch and hug when you have other diseases. But you are alone in this... You feel emotional hunger. Not being able to touch ... I missed hugging too much... (N1)

"You feel lonely. No matter how supportive people are, can they come and hug me? can they stay with me, can they sleep with me? This disease is experienced alone..." (N3)

\subsubsection{Subtheme 2.2. Frustration}

One of the nurses stated that s/he was very frustrated with the loss of smell; 
"I lost my sense of smell in quarantine. I started to smell something every day. I wondered if it would come back... dry coffee, liquid soap, detergent... I always had an expectation because I used medicine. Therefore, I was very frustrated during the quarantine..." (N17)

\subsubsection{Subtheme 2.3. Depressed mood}

Some of the nurses $(n=4)$ reported that they experienced depressive feelings during the quarantine process as follows;

"Well, everything is negative... It gives you a feeling of being depressed... You just want to rest, not want to see anyone, to sleep, and to do anything... there were feelings of depression ... Everything felt negative ... Even the best thing uttered bothered me..." (N15)

"During the quarantine, there is no social life, no social support, psychologically very bad, you feel like to be depressed...Psychologically, people are very worn out..." (N8)

\subsubsection{Subtheme 2.4. Fear of exclusion}

One of the nurses stated that they feared being excluded during the quarantine process and that this happened after the quarantine as follows;

"There were people who called, asked, and supported me in the quarantine. But the only thing I thought about in quarantine was exclusion... I wondered if people would approach me. Even though I was treated, I feared being excluded... and it happened... Nobody wants to stay near you, even my colleagues stay away from me even though I have been treated..." (N12)

\subsubsection{Subtheme 2.5. Fear of death}

Some of the nurses $(n=6)$ expressed that they were afraid of death due to shortness of breath;

"They wanted to hospitalize me, but I refused... I thought I could handle it at home, but the same symptoms started again after two hours ... I couldn't breathe, the fear of death appeared at that moment ..." (N4)

"When I thought about the first three days, I really felt that I was facing death... I was very scared... I felt like I was going to die when I couldn't breathe" (N13)

\subsection{Main Theme 3. Posttraumatic Growth}

Posttraumatic growth experienced by nurses after the diagnosis of COVID-19 was examined under four subthemes: spiritual change, changes in the relationship with others, changes in priorities, and appreciation of life.

\subsubsection{Subtheme 3.1. Spiritual change}

Most of the nurses $(n=7)$ stated that when they were diagnosed with COVID-19, they questioned their spiritual lives and went through a change as follows;

"Inevitably, death anxiety comes to your mind, and you question yourself. I realized how weak I was spiritually and even made a promise myself. I will pay more attention to my prayers after the treatment... I was very angry with myself as I was for living this way..." (N15)

"That's when I realized that everything was in vain, the only thing that is real is after death. ... I tended to question my mistakes and sins a little bit and leave them... I turned to God more." (N16)

\subsubsection{Subtheme 3.2. Changes in relationship with others}

Most of the nurses $(\mathrm{n}=7)$ reported that by revising their relationships with others, they experienced strengthening in some relationships and weakening in others. Some of the nurses' statements are as follows; 
"For example, people whom I don't normally meet much called me, I became so happy, you feel valuable. But the fact that the people I cared about, did a lot of things for and felt very close did not worry about me and did not call me caused me to revise and change my relationships..." (N1)

"My relationships got stronger. Many things happened... people around me called, bought our needs and left them at the door, and this strengthened our bonds." (N5)

\subsubsection{Subtheme 3.3. Changes in priorities}

Some of the nurses $(n=4)$ stated that being diagnosed with COVID-19 enabled them to experience changes in their priorities in life;

“... I realized that health is more important than anything else. That's why I decided not to worry about some things anymore, not to think too much, and not give so much importance. I understood better that the most important thing is health." (N16)

"We had a plan to save up and buy a detached house before the diagnosis. We used to save for it... I used to set aside a limited budget for our needs just to be able to buy a house. But then, our priorities have changed completely, I realized that our health and nutrition are more important and now I spend my budget on them..." (N15)

\subsubsection{Subtheme 3.4. Appreciation of life}

All the nurses stated that they realized the value of life and that making life meaningful is important as follows;

“... my perspective on life now and before this illness is different. How valuable breathing is, how valuable life is! You question more for what you live for, and you start living more meaningfully."(N1)

"I felt the need to live more meaningfully as the disease gave me another chance to live. I got more attached to life and understood its value more..." (N4)

"You understand that life is much more valuable... You understand and appreciate the meaning of life, and the value of even being able to taste and smell." (N6)

\subsection{Main Theme 4. Coping methods with COVID-19}

Most of the nurses expressed that they coped with the problems related to COVID-19 with the social support they received from the family and the environment, paying attention to nutrition, positive thinking, and engaging in their favourite domestic activities. The most significant facilitating factor that made it easier for them to overcome this period was social support, being a nurse, and a family member COVID-19 survivor. The factors that make it difficult were reported to be loneliness, frustration, fear of death, the severity of symptoms, fear of exclusion, death news on social media, being a nurse, having a child, and fear of infecting the family.

“... I got over it by trying to think positively. Because the moment I thought negatively, both psychologically and physiologically, I was getting worse and worse. I answered every phone call because social support made it easier for me to get through this difficult process. Also, the fact that someone in my family survived and recovered gave me morale. Because loneliness and the severity of the symptoms make this period challenging." (N1)

"I got through this process with social support. Also, because I am a nurse, I know what to do if I have a fever or can't breathe, so I got through. However, being a nurse and knowing is sometimes disadvantages because it makes it difficult to know what will happen if the process gets worse..." (N4)

"I watched TV, listened to music, surfed on social media, read books, tried to overcome the disease with them... I paid great attention to my diet. People wondering about you make you feel valuable. It's nice to feel loved." (N8) 


\subsection{Main Theme 5. Nursing Care After COVID-19 Treatment}

All the nurses stated that as someone who experienced the diagnosis and treatment process of COVID-19, they have started to empathize in nursing care and give more importance to psychological care that they neglected previously with the following sentences;

"Before going through this process, I was thinking that patients were exaggerating when they said they had pain. However, as someone who has experienced this, I understand them better now. I can say that this process enabled me to empathize..." (N1)

"I realized that we need to approach patients with empathy. I realized that patients especially needed psychological care and I used to neglect this in the care I provided. Normally, we neglect psychological care too much because we take care of many patients at the same time and there is no time left while trying to finish medical treatment. But I don't do that anymore..." (N11)

\subsection{Main Theme 6. Metaphors about COVID-19}

Nurses used a total of 17 metaphors about COVID-19. Only one of these metaphors is positive. One nurse stated that she did not compare COVID-19 anything, so as not to remember it in the future.

"Table 4 in here"

\section{DISCUSSION}

Being diagnosed with COVID-19 adversely affects the psychological health as well as the physical health of the individuals due to the lack of a proven drug for the treatment of the disease, severe or variable symptoms, high mortality, and loneliness during the quarantine/treatment (An et al., 2020; Chen et al., 2020; Karimi et al., 2020). A large number of current studies in the literature have examined the experiences of nurses caring for patients with COVID-19 (An et al., 2020; Kackin et al., 2020; Karimi et al., 2020; Tan et al., 2020; Zhang et al., 2020). However, no study to our knowledge has investigated the experiences of nurses diagnosed with COVID-19 yet. Experiences of nurses when they were diagnosed with COVID-19 were examined under six main themes in this study; emotions experienced when they learned to be COVID-19 positive, the emotions during the quarantine process, posttraumatic growth, the meaning of life, coping methods with COVID-19, nursing care after being positive for COVID-19 and metaphors of COVID-19.

\subsection{The emotions experienced when the nurses learned to be COVID-19 positive}

Nurses experienced many negative psychological symptoms such as fear, anger, depression, loneliness, frustration, exclusion, and fear of death when they were diagnosed with COVID-19 and during the quarantine process in this study. Qualitative studies carried out with nurses involved in the treatment of patients diagnosed with COVID-19 report that they experience anxiety, stress, fear, and anger (An et al., 2020; Aungsuroch et al., 2020; Kackin et al., 2020). Aungsuroch et al. (2020) noted that some patients diagnosed with COVID19 experienced a fear of death even though they had no symptoms of COVID-19. The statement of one of the patients in the same study is as follows: “... my mind made me think that I am between life and death because I believe COVID-19 is between life and death..." (Aungsuroch et al., 2020). As can be understood from the patient's statement, COVID-19 is associated with death, and it can cause fear, stress, and depression in nurses and patients struggling with the disease (Lu et al., 2020). Research has demonstrated that nurses suffer from depression, posttraumatic stress disorder, and anxiety disorder associated with burnout, hopelessness, apathy, fear, sleep problems, etc. during the pandemic (Lai et al., 2020; Ghasempour et al., 2020). Some of the nurses in this study experienced anger due to the delay in getting tested for COVID-19 and being forced to continue working despite showing some symptoms. Lack of nurse workforce in healthcare institutions, difficult working conditions, insufficient support of nurses by administrators and society, especially psychologically, caused nurses to have anger during the COVID-19 pandemic period (Kackin et al., 2020).

\subsection{The emotions during the quarantine process}


Similarly, various studies report that some individuals in quarantine experience a feeling of loneliness, frustration, and exclusion (Chen et al., 2020a; Fernandez et al., 2020; Lu et al., 2020; Shen et al., 2020). Especially, those living alone at home are afraid of being alone, and fear of death or staying in quarantine for a long time may cause individuals to miss the social life they are accustomed to and deepen loneliness (Fernandez et al., 2020; Lu et al., 2020). In one of the studies, one of the patients expressed the feeling of emptiness created by loneliness as follows; "...I usually manage very well alone. But now that all activities outside of my home have been cancelled, this is very difficult. My skin is dying to be touched and hugged. But no hugging..." (Schellekens \& van der Lee, 2020). In this study, one of the nurses was afraid of being excluded because she was diagnosed with COVID-19 and it happened even by her colleagues after treatment. Chen et al. (2020) argued that regardless of whether they were diagnosed with COVID-19 or not, individuals who experience the quarantine process due to contact can be seen as a potential source of virus in the society, and interaction with these individuals is avoided (Chen et al., 2020a). This situation may cause the individual to experience a feeling of exclusion.

\subsection{Posttraumatic growth}

As a result of dealing with traumatic events that are associated with death, such as COVID-19, people can experience positive changes in areas such as spiritual and existential change, improvement in personal power, changes in relationships with others, new opportunities, and appreciation of the meaning of life through posttraumatic growth (PTG) (Tamiolaki \& Kalaitzaki, 2020; Tedeschi \& Moore, 2020). In this study, most of the nurses have started to question the spiritual aspect of their lives after being diagnosed with COVID-19 and will pay more attention to improve these aspects, experience changes in relationships with others and priorities in life and appreciate the value of life more. Chen et al. (2021) highlighted that nurses who care for COVID-19 patients in intensive care understand the value of life better than those working in other units and show more positive changes concerning relationships, new opportunities, personal power, and spiritual change (Chen et al., 2021). In another study, nurses serving in wars experienced an understanding of the value of life, personal power, and spiritual and existential change in the fields of PTG (Ellen Doherty et al., 2020). Nurses caring for patients diagnosed with COVID-19 witness the symptoms of the disease in humans. It is inevitable to witness the positive changes in nurses who care for COVID-19 patients and nurses who are diagnosed with COVID-19, and these changes make it easier for individuals to cope with the traumatic event.

\subsection{Coping methods with COVID-19}

Individuals develop various methods to cope with the challenging situations caused by traumatic events such as diseases, natural disasters, etc. (Huang et al., 2020). In this study, nurses diagnosed with COVID-19 try to cope with the disease by thinking positively, doing indoor activities they like, taking care of their nutrition, and getting social support from the people around them. According to the results, social support and having a family member who is a COVID-19 survival makes it easier to cope with this process while loneliness, frustration, fear, the severity of symptoms, fear of exclusion, negative news on social media, being a nurse, having a child and the fear of infecting family members complicates the process. In a qualitative study conducted by Munawar and Riaz-Choudhry (2020), emergency healthcare workers try to avoid the conversations about giving care to patients diagnosed with COVID-19 and trying to get over the period by using spiritual coping methods and reducing following the news and social media. In the same study, one of the participants stated that $\mathrm{s} /$ he was relieved by using religion as a coping method by expressing that “... My coping method is based on my belief that every disaster/disease/virus comes from Allah (God) ... I believe that the virus is a test, and God helps me to cope with it, and I relax every time I remind myself of this..." (Munawar \& Riaz Choudhry, 2020). Another relevant study cites that individuals tried to cope with the disease by exercising, watching movies, listening to music, reading books, spending time with children and family members, doing gardening, calling loved ones, praying to God, eating more, and thinking less about COVID-19 (Aziz Rahman et al., 2020). However, individuals may not always use positive coping methods. Negative methods (alcohol, increased smoking, etc.) are also used to cope with the psychological crisis caused by the COVID-19 pandemic (Chodkiewicz et al., 2020; Stanton et al., 2020). The most significant reason 
for using positive coping methods in this study may be that the participants were health professionals and knew how the process would progress when negative coping methods were used.

\subsection{Nursing care after being positive for COVID-19}

From the point of view of nurses, empathy is one of the most significant components pivotal to understand the needs, feelings, and condition of patients and prove nursing care accordingly (Ghaedi et al., 2020; Moudatsou et al., 2020). Understanding what any patient experiences and feels due to their illness can positively affect the care nurses provide (Barello \& Graffigna 2020; Ghaedi et al., 2020). This study revealed that nurses diagnosed with COVID-19 developed a sense of empathy and started to provide more psychological support to patients. Hyeon-Jin et al. (2019) observed a positive relationship between the empathy levels of nurses and the nursing care given to the elderly. Some nurses do not provide adequate nursing care to patients, considering that patients reflect the symptoms in an exaggerated way. However, with the COVID-19, nurses who personally experienced the psychological effects of the disease increased psychological support while caring for patients since they were able to empathize more.

\subsection{Metaphors of COVID-19}

The use of metaphors is one of the most effective ways to reveal how the individual makes sense and perceives the situation he/she lives in and what kind of impact it has on her/him (Sabucedo et al., 2020). In this study, almost all the nurses described COVID-19 with 17 negative metaphors (poison, death, black box, drowning, despair, etc.). Research shows that COVID-19 is often expressed using the metaphor of war (Chapman \& Miller, 2020; Sabucedo et al., 2020; Benziman, 2020). In a study by Semino (2020), COVID-19 is compared to a tsunami on healthcare services. The fact that COVID-19 is mostly defined by people with negative concepts is due to its negative impact on all humanity in all aspects.

\subsection{Limitation and Strength}

The study has some limitations. The interviews were conducted over the telephones, so the feelings of the nurses while describing their experiences could not be understood by facial expressions/gestures, and the nurses included in the study were interviewed only once. The scientific rigor of the study is that nurses from every region of Turkey participated in the research, and the data are presented based on Meleis Transition Theory. With these features, it is believed that this study will fill the gap in the literature and shed light on further studies.

\section{CONCLUSION}

The study showed that nurses diagnosed with COVID-19 experienced fear, loneliness, frustration, depressed mood, exclusion and fear of death. After the treatment of COVID-19, nurses experienced posttraumatic growth in the areas of spiritual change, changes in relationships with others, changes in priorities, and appreciation of life. Besides, it was observed that nurses neglected psychological care in patient care before being diagnosed with COVID-19 and displayed a less empathetic approach. However, after being diagnosed with COVID-19 and experiencing the symptoms of the disease, nurses develop a sense of empathy towards patients. Nurses reported that they coped with the symptoms caused by COVID-19 by getting social support, paying attention to nutrition, thinking positively, and engaging in domestic activities. COVID-19 is defined by most of the nurses with negative metaphors.

\section{RELEVANCE TO CLINICAL PRACTICE}

- Nurses are both physically and psychologically worn out due to difficult working conditions, fear of being infected and transmitting the virus, quarantine process, and fear of death, etc, during their struggle against COVID-19. These problems are more severe in those diagnosed with COVID-19. To reduce these problems, it is recommended to provide professional psychological consultancy services and to ensure these services $24 / 7$ online or offline.

-Nurses encounter social exclusion due to their potential for virus transmission. This attitude causes psychological destruction of nurses, who are at the frontline and described as "heroes" by society in the struggle 
with COVID-19 that threatens all humanity. To eliminate this problem, it will be beneficial to raise the awareness of society by making publications aimed at preventing such behaviours against health professionals, especially nurses, through social media and mass media.

\section{What does this paper contribute to the wider global clinical community?}

-The study demonstrated that nurses diagnosed with COVID-19 experienced fear, loneliness, frustration, depressive mood, exclusion, and fear of death.

- They also achieve progress in the areas of posttraumatic growth such as spiritual change, changes in the relationship with others, changes in priorities, and appreciation of the meaning of life after COVID-19 treatment.

-It is also noteworthy that nurses expressed that they neglected the psychological care of patients and displayed a less empathetic approach before they got the disease.

-Being diagnosed with COVID-19 contributed nurses to improve their sense of empathy towards patients.

-They reported that they coped with the difficulties caused by COVID-19 by getting social support, paying attention to nutrition, thinking positively, and doing domestic activities.

-Nurses generally describe COVID-19 with negative metaphors (poison, drowning, death, etc.).

\section{REFERENCES}

An, Y., Yang, Y., Wang, A., Li, Y., Zhang, Q., Cheung, T., Ungvari, G. S., Qin, M. Z., An, F. R., \& Xiang, Y. T. (2020). Prevalence of depression and its impact on quality of life among frontline nurses in emergency departments during the COVID-19 outbreak. Journal of Affective Disorders; 276: 312315.https://doi.org/10.1016/j.jad.2020.06.047. Aungsuroch, Y., Gede, J.I., \& Joko, G. (2020). Experiences of patients with Coronavirus in the COVID-19 pandemic era in Indonesia. Asian Journal of Public Opinion Research, 8(3), 377-392.https://doi.org/10.15206/ajpor.2020.8.3.377. Barello, S., \& Graffigna, G. (2020). Caring for health professionals in the COVID-19 pandemic emergency: Toward an "epicemid of empathy" in healthcare. Frontiers in Psychology, 11, 1-4.https://doi.org/10.3389/fpsyg.2020.01431. Benziman, Y. (2020). "Winning" the "battle" and "beating" the COVID-19 "enemy". Leaders' use of war frames to define the pandemic.Peace and Conflict-Journal of Peace Psychology, 26(3):247-256.https://doi.org/10.1037/pac0000494. Braun, V., \& Clarke, V. (2014). What can "thematic analysis" offer health and wellbeing researchers?. International Journal of Qualitative Studies on Health and Well-Being, 9. Doi:10-3402/qhw.v9.26152. Chapman, C. M., \& Miller, D. S. (2020). From metaphor to militarized response: The social implications of "we are at war with COVID-19"-crisis, disasters, and pandemics yet to come.International Journal of Sociology and Social Policy, 40(9-10), 1107-1124.https://doi.org/10.1108/IJSSP-05-2020-0163. Chen, D., Song, F., Tang, L., Zhang, H., Shao, J., Qiu, R., Wang, X., \& Ye, Z. (2020a). Quarantine experience of close contacts of COVID-19 patients in China: A qualitative descriptive study. General Hospital Psychiatry, 66, 81-88.https://doi.org/10-1016/j.genhosppsych.2020.07.006. Chen, N., Zhou, M., Dong, X., Qu, J., Gong, F., Han, Y., Qiu, Y., Wang, J., Liu, Y., Wei, Y., Xia, J., Yu, T., Zhang, X., \& Zhang, L. (2020). Epidemiological and Clinical Characteristics of 99 Cases of 2019 Novel Coronavirus Pneumonia n Wuhan, Chine: A Descriptive Study.Lancet, 395: 507-513.https://doi.org/10.1016/S0140-6736(20)302117. Chen, R., Sun, C., Chen, J. J., Jen, H. S., Kang, X. L., Kao, C. C., \& Chou, K. R. (2021). A large-scale survey on trauma, burnout, and posttraumatic growth among nurses during the COVID-19 pandemic.International Journal of Mental Health Nursing, 30, 102-116.https://doi.org/10.1111/inm.12796. Chodkiewicz, J., Talarowska, M., Miniszewska, J., Nawrocka, N., \& Bilinski, P.(2020). Alcohol consumption reported during the COVID-19 pandemic: The initial stage. International Journal of Environmental Research and Public Health, 17(13), 1-11.https://doi.org/10.3390/ijerph17134677. Creswell, J. W., \& Poth, C. N. (2016). Qualitative inquiry and research design: Choosing among five approaches. Sage Publications. Çelik, S. Ş., Özbaş, A. A., Çelik, B., Karahan, A., Bulut, H., Koç, G., Çevik, A. F., Özdemir, Ö. Ç. (2020). The COVID-19 Pandemic: Turkish Nurses Association. Journal of Education and Research in Nursing, 7(3): 279-83 Doi:10.5222/Kuhead.2020.34603. Doherty, M. E., Scannell-Desch, 
E., \& Bready, J. (2020). A positive side of deployment: Vicarious posttraumatic growth in U.S. military nurses who served in the Iraq and Afghanistan wars. Journal of Nursing Scholarship, 52, 3, 233241.https://doi.org/10.1111/jnu.1254\%. Fernandez, R., Lord, H., Halcomb, E., Moxham, L., Middleton, R., Alananzeh, I., \& Ellwood, L. (2020). Implications for COVID-19: A systematic review of nurses' experiences of working in acute care hospital settings during a respiratory pandemic. International Journal of Nursing Studies, 111, 1-8.https://doi.org/10.1016/j.ijnurstu.2020.103637. Gashi, F. (2020). The Effect of Religious Coping During the Treatment Period of People Who Are Caught Coronavirus. Pamukkale University Journal of Divinity Faculty, 7(1): 511-535.https://doi.org/10.17859/pauifd.735931. Ghaedi, F., Ashouri, E., Soheili, M., \& Sahragerd, M. (2020). Nurses' empathy in different wards: A cross-sectional study. Iranian Journal of Nursing and Midwifery Research, 25(2), 117-121. Doi:10.4103/ijnmr.IJNMR_84_19. Ghaljaie, F., Naderifar, M., \& Goli, H. (2017). Snowball sampling: A purposeful method of sampling in qualitative research. Strides in Development of Medical Education, 14(3). Doi:10.5812/sdme.67670. Huang, L., Lei, W., Xu, F., Liu, H., $\& \mathrm{Yu}, \mathrm{L}$. (2020). Emotional responses and coping strategies in nurses and nursing students during COVID19 outbreak: A comparative study. PLOS ONE, 15(8), 1-12.https://doi.org/10.1371/journal.pone.0237303. Hyeon Jin, N., Eun-Jeong, K., \&So-Hyeon, S. (2019). Influences of nurses' empathy and self-efficacy on nursing care of older adults in an integrated nursing care services (INCS) unit. Journal of East-West Nursing Research, 25(1), 9-16.https://doi.org/10.14370/jewnr.2019.25.1.9. Kackin, O., Ciydem, E., Aci, S. O. , \& Kutlu, F. M. (2020). Experiences and Psychosocial Problems of Nurses Caring for Patients Diagnosed with COVID-19 in Turkey: A Qualitative Study. International Journal of Social Psychiatry, 1-10. Doi: 10.1177/0020764020942788. Karasu, F., \& Öztürk Çopur E (2020). An Intensive Care Nurse in The Forefront of The Epidemic While Increasing Cases of COVID-19: "Heroes in Front-Line". Yoğun Bakım Hemşireliği Dergisi; 24(1): 11-14. Karimi, Z., Fereidouni, Z., Behnammoghadam, M., Alimohammadi, N., Mousavizadeh, A., Salehi, T., Mirzaee, M. S., \& Mirzaee, S. (2020). The lived experience of nurses caring for patients with COVID-19 in Iran: A phenomenological study. Risk Management and Healthcare Policy, 13, 1271-1278. Doi: 10.2147/RMHP.S258785. Lai, J., Ma, S., Wang, Y., Cai, Z., Hu, J., Wei, N., Wu, J., Du, H., Chen, T., Li, R., Tan, H., Kang, L., Yao, L., Huang, M., Wang, H., Wang, G., Liu, Z., \& Hu, S. (2020). Factors associated with mental health outcomes among health care workers exposed to coronavirus disease 2019. JAMA Network Open. 2020;3(3):e203976. Doi: 10.1001/jamanetworkopen.2020.3976. Lu, H., Nie, P., \& Qian, L. (2020). Do quarantine experiences and attitudes towards COVID-19 affect the distribution of mental health in China? A quantile regression analysis. Applied Research in Quality of Life, 1-18.https://doi.org/10.1007/s11482020-09851-0. Meleis, A. I. (2010). Transitions theory: Middle range and situation specific theories in nursing research and practice. Springer Publishing Company. Meleis, A. I., Sawyer, L. M., Im, E. O., Messias, D. K. H., \& Schumacher, K. (2000). Experiencing transitions: an emerging middle-range theory. Advances in Nursing Science, 23(1), 12-28. Morse, J. M. (2015). Data were saturated. Qualitative Health Research, 25(5), 587-588.https://doi.org/10.1177\%2F1049732315576699. Moudatsou, M., Stavropoulou, A., Philalithis, A., \& Koukouli, S. (2020). The role of empathy in health and social care professionals. Healthcare, 8(26), 1-9.https://doi.org/10.3390/healthcare8010026. Munawar, K., \& Riaz, C. F. (2020). Exploring stress coping strategies of frontline emergency health workers dealing Covid-19 in Pakistan: A qualitative inquiry. American Journal of Infection Control, 1-7.https://doi.org/10.1016/j.ajic.2020.06.214. Purabdollah, M., Ghasempour, M. (2020). Necessity of attention to mental health of the front line nurses against COVID-19: A forgotten requirement. International Journal of Community Based Nursing E3 Midwifery, 8(3):280-281. Doi:10.30476/IJCBNM.2020.85889.1301. Rahman, M. A., Hoque, N., Alif, S.M., Salehin, M., Islam, S. M. S, Banik, B., Sharif, A., Nazim, N. B., Sultana, F., \& Cross, W. (2020). Factors associated with psychological distress, fear and coping strategies during COVID-19 pandemic in Australia. Globalization and Health, 16(1), 1-15.https://doi.org/10.1186/s12992-020-00624-w. Republic of Turkey Ministry of Health (2020). General coronavirus picture.https://covid19.saglik.gov.tr/TR-66935/genel-koronavirus-tablosu.html.Sabucedo, J. M., Alzate, M., \& Hur, D. (2020). COVID-19 and the metaphor of war. International Journal of Social Psychology, 35(3), 618-624.https://doi.org/10.1080/02134748.2020.1783840. Schellekens, M. P., van der Lee, M. L. (2020). Loneliness and belonging: Exploring experiences with the COVID-19 pandemic in psycho-oncology. Psycho-Oncol, 29(9), 1399-1401.https://doi.org/10.1002/pon.5459. Schumacher, K. L., \& Meleis, A. L. (1994). Transitions: A central concept in nursing. Image: The Journal of Nursing Schol- 
arship, 26(2), 119-127.https://doi.org/10.1111/j.1547-5069.1994.tb00929.x. Schwartz, J., Chuen King, C., \&Yong Yen, M. (2020). Protecting Health Care Workers During The COVID-19 Coronavirus OutbreakLessons From Taiwan's SARS Response. Clin Infect Dis; 71(15): 858-860. Doi: 10.1093/cid/ciaa255. Semino E (2020). "Not soldiers but fire-fighters"-Metaphors and COVID-19. Health Communication, 36(1), 50-58.https://doi.org/10.1080/10410236.2020.1844989. Shen, X., Zou, X., Zhong, X. Yan, J., \& Li, L. (2020). Psychological stress of ICU nurses in the time of COVID-19. Critical Care, 24, 200, 13.https://doi.org/10.1186/s13054-020-02926-2. Silverman, D. (Ed.). (2020). Qualitative research. Sage Publications Limited. Stanton, R., To, Q. G., Khalesi, S., Williams, S. L., Alley, S. J., Thwaite, T. L., Fenning, A. S., \&Vandelanotte, C. (2020). Depression, anxiety and stress during COVID-19: Associations with changes in physical activity, sleep, tobacco and alcohol use in Australian adults.International Journal of Environmental Research and Public Health, 17(11), 1-13.https://doi.org/10.3390/ijerph17114065. Sun, N., Shi, S., Jiao, D., Song, R., Ma, L., Wang, H., Wang, C., Wang, Z., You, Y., Liu, S., \& Wang, H. (2020). A qualitative study on the psychological experience of caregivers of COVID-19 patients. American Journal of Infection Control, 48, 592-598.https://doi.org/10.1016/j.ajic.2020.03.018. Tamiolaki, A., Kalaitzaki, A. E. (2020). "That which does not kill us, makes us stronger": COVID-19 and posttraumatic growth. Psychiatry Research, 289, 1-2. Doi:10.1016/j.psychres.2020.113044. Tan, R., Yu, T., Luo K., Teng, F., Liu, Y., Luo, J., \& Hu, D (2020). Experiences of clinical first-line nurses treating patients with COVID-19: A qualitative study. Journal of Nursing Management, 28, 1381-1390.https://doi.org/10.1111/jonm.13095. Tedeschi, R. G., \& Moore, B.A. (2020). Posttraumatic growth as an integrative therapeutic philosophy. Journal of Psychotherapy Integration.https://doi.org/10.1037/int0000250. World Health Organisation (2020). Weekly epidemiological update - 15 December 2020https://www.who.int/publications/m/item/weekly-epidemiologicalupdate-15-december-2020. Zhang, M. M., Niu, N., Zhi, X. X., Zhu, P., Wu, B., Wu, B. N., Meng, A. F., \& Zhao, Y. (2020). Nurses' psychological changes and coping strategies during home isolation for the 2019 novel coronavirus in China: A qualitative study. Journal of Advanced Nursing, 77:308-317. Doi: 10.1111/jan.14572

\section{Hosted file}

Tables.docx available at https://authorea.com/users/396678/articles/509795-experiences-ofnurses-diagnosed-with-covid-19

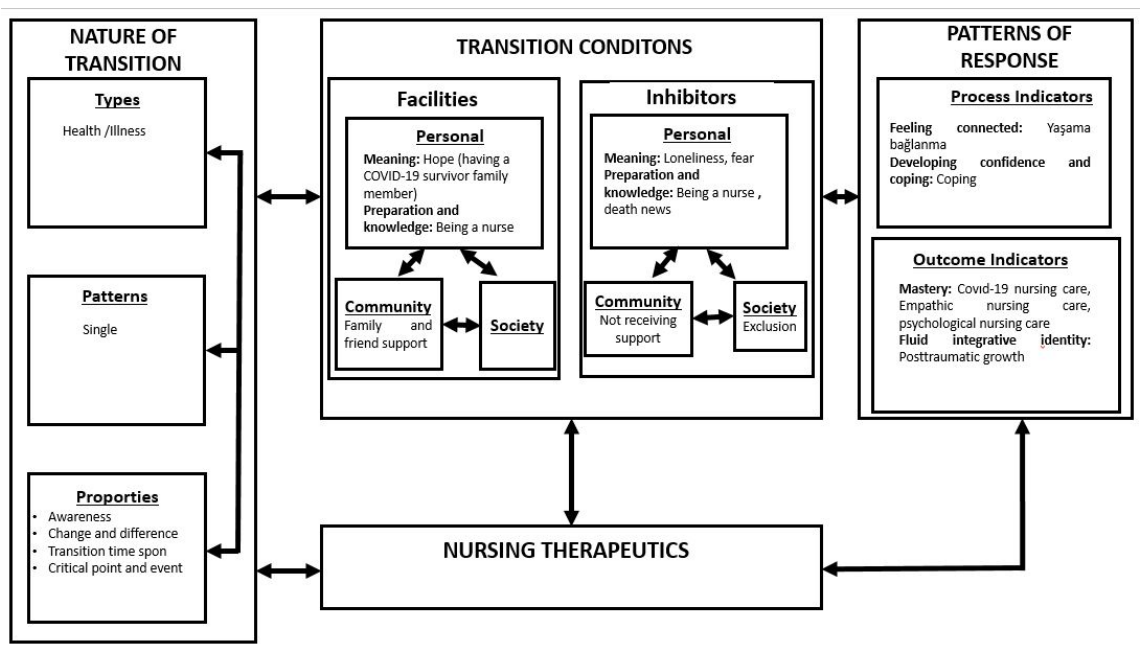

